\title{
PREVALENCE OF DIABETIC RETINOPATHY IN THE DUBROVNIK-NERETVA COUNTY
}

\author{
Antonela Gverović Antunica ${ }^{1}$, Kajo Bućan², Snježana Kaštelan ${ }^{3}$, Helena Kaštelan ${ }^{1}$, Mira Ivanković4, Maja Šikić \\ ${ }^{1}$ Department of Ophthalmology, General Hospital Dubrovnik, Dubrovnik, Croatia \\ ${ }^{2}$ University Department of Ophthalmology, Clinical Hospital Split, Split, Croatia \\ ${ }^{3}$ Department of Ophthalmology, Clinical Hospital Dubrava, Zagreb, Croatia \\ ${ }^{4}$ Department of Neurology, General Hospital Dubrovnik, Dubrovnik, Croatia \\ ${ }^{5}$ Medical Centre Dubrovnik, Dubrovnik, Croatia
}

\begin{abstract}
SUMMARY
Objective: Diabetic retinopathy is one of the leading causes of blindness. We estimated the prevalence of diabetic retinopathy among a diabetic population in the Dubrovnik-Neretva County in the Republic of Croatia and searched for potential risk factors.

Methods: A prospective study was performed with 600 diabetic patients from different parts of the Dubrovnik-Neretva County who attended regular medical and ophthalmological check-ups at the General Hospital Dubrovnik from September 2014 to September 2015. Patients underwent a complete medical assessment by two ophthalmologists. Retinal examination included evaluation of the presence of diabetic retinopathy. Any retinopathy present was graded as mild non-proliferative retinopathy, moderate-severe non proliferative retinopathy or proliferative retinopathy.

Results: Retinopathy was present in $44.5 \%$ of the study sample. $20.7 \%$ had the mild form of diabetic retinopathy, $18.8 \%$ had the moderate-severe form, and $5.0 \%$ had proliferative diabetic retinopathy. The mean duration of diabetes was 12.94 years $\pm 6.85 ; 12.89$ years \pm 9.18 in men, 12.94 \pm 6.54 in women. The mean BMI was $27.14 \pm 2.98$; for diabetics without diabetic retinopathy $26.19 \pm 2.75$; for those with the mild form $28.06 \pm$ 3.01 ; for those with the moderate-severe form $28.49 \pm 2.54$; for those with proliferative diabetic retinopathy $28.79 \pm 3.16 .168(28 \%)$ patients were treated by laser and $22(3.7 \%)$ by vitrectomy.

Conclusion: The prevalence of diabetic retinopathy in the Dubrovnik-Neretva County is $44.5 \%$. Regular screening to detect diabetic retinopathy is highly recommended as timely intervention can prevent most diabetic causes of blindness.
\end{abstract}

Key words: prevalence, diabetic retinopathy, Dubrovnik-Neretva county, duration of diabetes

Address for correspondence: A. Gverović Antunica, Department of Ophthalmology, General Hospital Dubrovnik, Roka Mišetića bb, 20000 Dubrovnik, Croatia. E-mail: agantonela@net.hr

https://doi.org/10.21101/cejph.a5213

\section{INTRODUCTION}

Diabetes mellitus (DM) constitutes a major health problem for all age groups in many countries, affecting about 180 million people worldwide (1). As a result of population growth, ageing, obesity and inactive lifestyle, it is estimated that the total number of people with diabetes will rise, particularly in developing countries, resulting in 300 million cases by the year 2025 (2). The growing number of diabetic patients will inevitably lead to an increased prevalence of macrovascular and microvascular diabetic complications including diabetic retinopathy (DR).

DR is a common and progressive microvascular complication of diabetes and despite the availability of effective treatment it remains one of the leading causes of vision impairment and blindness in working-age adults (3). It affects three-quarters of individuals who have had diabetes mellitus for more than 15 years (1). According to the Wisconsin epidemiologic study of diabetic retinopathy (WESDR), $3.6 \%$ of patients with type 1 and $1.6 \%$ of patients with type 2 diabetes were considered legally blind; $86 \%$ of legal blindness in type 1 , and $33 \%$ in type 2 diabetic patients was attributable to DR (4).

Retinopathy may lead to increased morbidity, disability and even mortality and therefore represents a major health problem in patients with diabetes. Since this unavoidably puts a great burden on healthcare system, diminishing the influence of this complication becomes highly desirable.

Despite the gravity of potential risks of diabetic complications, to our best knowledge, no study has been undertaken to estimate the impact of this problem in the Republic of Croatia. Our study aims to report the prevalence of diabetic retinopathy, its types, and patient characteristics in a diabetic population in the Dubrovnik-Neretva County, the southernmost region of the Republic of Croatia. Identification of potential risk factors and particularly high-risk groups becomes important for the assessment and amendment of strategies and planning of public health policies on the prevention and treatment of diabetic retinopathy. 


\section{MATERIALS AND METHODS}

\section{Patients}

The Dubrovnik-Neretva County in the Republic of Croatia is located on the Adriatic coast. It encompasses an area of 1,785 $\mathrm{km}^{2}$ and has 122,879 residents. Territorially, it is organized into 22 local self-administration units, divided into 5 cities, and 17 municipalities. The centre of County is the City of Dubrovnik.

This study included 600 patients with diabetes from different parts of the county who attended regular medical and ophthalmological check-ups in Dubrovnik General Hospital from September 2014 to September 2015. The sample group in this study is estimated to represent $20 \%$ of the known total diabetic population in the County.

\section{Data Collection Procedures}

All patients underwent a standardized interview, medical examination (including collection of blood samples) and a thorough eye examination.

A full medical history was taken from each patient including age at time of examination, age at time of diabetes diagnosis (first recorded by a physician), duration of diabetes (time between age at diagnosis and age at time of examination), family history, type of diabetes (based on the World Health Organization (WHO) classification) (5), smoking status, alcohol intake, and medication. Additionally, a history of chronic disease including hypertension, ischaemic heart disease, cerebral stroke, terminal renal disease, and glaucoma was recorded. The diabetic treatment status was recorded as diet only, oral hypoglycaemics or insulin treatment. Patients on both oral hypoglycaemics and insulin were categorized as insulin dependent. Blood pressure was measured early in the morning in a sitting position in both arms using a standard mercury sphygmomanometer. Hypertension was defined as the presence of systolic blood pressure (SBP) $>140 \mathrm{mmHg}$ and diastolic blood pressure (DBP) $>90 \mathrm{mmHg}$ or use of antihypertensive medications. Height was measured without shoes and weight recorded while wearing indoor clothing. Using the height and weight measurement results, body mass index (BMI) was calculated (weight in kilograms, divided by height in meters squared). The WHO classification for BMI was used to estimate the degree of weight excess (5) being defined minimally as a BMI $\geq 25 \mathrm{~kg} / \mathrm{m}^{2}$. Fasting venous blood samples were collected and sent for analysis of serum lipid levels including total cholesterol, high-density lipoprotein (HDL), low-density lipoprotein (LDL), and triglycerides, glycated haemoglobin $\left(\mathrm{HbA}_{1} \mathrm{c}\right)$, glucose and creatinine at the laboratory at Dubrovnik General Hospital. $\mathrm{HbA}_{1} \mathrm{c}$ less than $7 \%$ was considered to indicate good glycaemic control. Hypercholesterolemia was defined as total cholesterol level of $\geq 6.2 \mathrm{mmol} / 1$ or use of lipidlowering drugs. Dyslipidaemia was taken to be present when total cholesterol was $>5.6 \mathrm{mmol} / 1$ and/or triglycerides $>2.10 \mathrm{mmol} / 1$, $\mathrm{LDL}>3.4 \mathrm{mmol} / 1$, and/or HDL $<0.91 \mathrm{mmol} / \mathrm{l}$ (5).

\section{Diagnosis of Diabetic Retinopathy}

Ophthalmologic assessments were performed by two ophthalmologists (experienced retinal specialist) and included measurement of visual acuity with Snellen chart, applanation tonometry with the Goldman tonometer, slit lamp biomicroscopy of the anterior eye segment and ophthalmoscopy. After pupil dilatation with topical $1 \%$ tropicamide detailed fundus examination for presence of diabetic retinopathy was performed using a Volk TransEquator lens. Assessment was carried out on seven fields and the diagnosis and pathological retinal findings were carefully recorded. In all the patients in whom diabetic retinopathy was established, fluorescein angiography was conducted. Any retinopathy presented in this study was classified as mild non-proliferative diabetic retinopathy (NPDR), moderate-severe NPDR and proliferative diabetic retinopathy (PDR) according to the summed interpretation of fluorescein angiography and the recorded ophthalmoscopic grading, using a scale modified from the Airlie House grading system (6). The severity of retinopathy was determined according to the grading of the seriously affected eye. Legal blindness was defined as best corrected visual acuity of $0.1(6 / 60)$ or less in the better eye.

\section{Statistical Analysis}

Descriptive and inferential statistics were used for data analysis. Mean and \pm standard deviation, and percentages were used as descriptive parameters of quantitative variables, y significant. Differences in distributions of categorical data were evaluated by Chi-square test and comparison of means by $\mathrm{T}$ test. Statistical significance was set at the 0.05 probability level. All statistical analyses were performed with the SPSS 13.0 software (SPSS Inc., Chicago, IL, USA).

\section{RESULTS}

We screened 600 patients with diabetes, the majority $(90.83 \%)$ had DM type 2.

The mean age was 65.37 years overall, 38.9 years for DM type 1 in men, 33.9 years for DM type 1 in women; 66.41 years for DM type 2 in men, and 70.25 years for DM type 2 in women. The mean duration of diabetes diagnosis was 12.94 years overall, 12.89 years in men and 12.94 in women.

The prevalence of DR in patients with diabetes in our sample was $44.5 \%, 20.7 \%$ had the mild form, $18.8 \%$ had the moderatesevere form and $5.0 \%$ had PDR; $168(28 \%)$ patients were treated by laser and $22(3.7 \%)$ by vitrectomy.

Concerning the risk factors hypercholesterolemia was present in $16 \%$ of participants, hypertriglyceridemia in $9.67 \%$, and glaucoma in $12.17 \%$, while $26(4.44 \%$ ) of patients were legally blind. The overall mean BMI was 27.14; in diabetics without DR 26.19, in diabetics with mild DR 28.06, in those with the moderate-severe form 28.49, and in those with PDR 28.79. All characteristics of the patients can be seen in Table 1 .

No consistent association between gender and DR prevalence in persons with diabetes was observed $(p=0.399)$. While the duration of diabetes, raised BMI and elevated cholesterol level were significantly associated with an increased risk of DR. Conversely, hypertension and elevated triglycerides levels were not significantly associated with an increased risk of DR (Table 2). 55 patients with DM type 1 were qualified for the study, 18 of them had retinopathy, while among 545 patients with DM type 249 patients had diabetic retinopathy diagnosed. The association between the duration of diabetes and level of retinopathy is presented in Table 3. 
Table 1. Demographic and clinical characteristics of patients with diabetes in the Dubrovnik-Neretva County, 2015-2016 ( $N=600)$

\begin{tabular}{|c|c|c|c|c|c|c|}
\hline & \multicolumn{2}{|c|}{ Diabetes mellitus type 1} & \multicolumn{2}{|c|}{ Diabetes mellitus type 2} & \multicolumn{2}{|c|}{ Total } \\
\hline & \multicolumn{2}{|c|}{$n=55$} & \multicolumn{2}{|c|}{$n=545$} & \multicolumn{2}{|c|}{$N=600$} \\
\hline & $\mathrm{n}$ & $\%$ & $\mathrm{n}$ & $\%$ & $\mathrm{n}$ & $\%$ \\
\hline \multicolumn{7}{|l|}{ Sex } \\
\hline Male & 30 & 9.7 & 279 & 90.3 & 309 & 51.6 \\
\hline Female & 25 & 8.6 & 266 & 91.4 & 291 & 48.4 \\
\hline \multicolumn{7}{|l|}{ Age group (years) } \\
\hline$<40$ & 32 & 58.2 & 1 & 0.2 & 33 & 5.5 \\
\hline $40-49$ & 8 & 14.6 & 17 & 3.2 & 25 & 4.2 \\
\hline $50-59$ & 11 & 20.0 & 78 & 14.4 & 89 & 14.8 \\
\hline $60-69$ & 2 & 3.6 & 192 & 35.3 & 194 & 32.3 \\
\hline $70-79$ & 1 & 1.8 & 209 & 38.3 & 210 & 35.0 \\
\hline$>80$ & 1 & 1.8 & 48 & 8.8 & 49 & 8.2 \\
\hline \multicolumn{7}{|c|}{ Duration of diabetes mellitus (years) } \\
\hline$\leq 1$ & 0 & 0 & 9 & 1.7 & 9 & 1.5 \\
\hline $2-5$ & 10 & 18.2 & 44 & 8.1 & 54 & 9.0 \\
\hline $6-10$ & 16 & 29.1 & 140 & 25.7 & 156 & 26.0 \\
\hline $11-15$ & 15 & 27.3 & 213 & 39.1 & 228 & 38.0 \\
\hline $16-20$ & 4 & 7.3 & 79 & 14.5 & 83 & 13.8 \\
\hline$\geq 21$ & 10 & 18.2 & 60 & 11.0 & 70 & 11.7 \\
\hline \multicolumn{7}{|l|}{$\mathrm{HbA}_{1} \mathrm{C}$} \\
\hline Good control & 33 & 60.0 & 218 & 40.0 & 251 & 41.8 \\
\hline Poor control & 22 & 40.0 & 327 & 60.0 & 349 & 58.2 \\
\hline Hypertension & 17 & 30.9 & 376 & 62.9 & 393 & 65.5 \\
\hline \multicolumn{7}{|l|}{ Stage of retinopathy } \\
\hline No retinopathy & 37 & 67.3 & 296 & 54.3 & 333 & 55.5 \\
\hline Mild NPDR & 6 & 10.9 & 118 & 21.7 & 124 & 20.7 \\
\hline Moderate-severe NPDR & 8 & 14.5 & 105 & 19.3 & 113 & 18.8 \\
\hline Proliferative retinopathy & 4 & 7.3 & 26 & 4.8 & 30 & 5.0 \\
\hline \multicolumn{7}{|l|}{ Comorbidity } \\
\hline Hypercholesterolemia & 14 & 25.5 & 82 & 15.1 & 96 & 16.0 \\
\hline Hypertriglyceridemia & 5 & 9.1 & 63 & 11.6 & 58 & 9.7 \\
\hline Haemodialysis & 3 & 5.5 & 8 & 1.5 & 11 & 1.8 \\
\hline Amputation & 1 & 1.8 & 17 & 3.1 & 18 & 3.0 \\
\hline Cerebro-vascular incident & 1 & 1.8 & 11 & 2.0 & 12 & 2.0 \\
\hline Glaucoma & 3 & 5.5 & 70 & 12.8 & 73 & 12.2 \\
\hline Legally blind & 5 & 9.1 & 21 & 3.9 & 26 & 4.3 \\
\hline \multicolumn{7}{|l|}{ Treatment } \\
\hline Laser & 13 & 23.6 & 155 & 28.4 & 168 & 28.0 \\
\hline Pars plana vitrectomy & 4 & 7.3 & 20 & 3.7 & 24 & 4.0 \\
\hline
\end{tabular}

$\mathrm{HbA}_{1} \mathrm{C}$ - glycated haemoglobin; NPDR - non-proliferative diabetic retinopathy

\section{DISCUSSION}

Recent studies show an increasing prevalence of diabetes and DR across the globe $(3,7,8)$. To our best knowledge this is the first attempt to estimate the prevalence rates of DR among diabetic patients in the Dubrovnik-Neretva County in the Republic of Croatia. Our purpose was to quantify the degree of DR problem in patients with diabetes in our county and reveal which patient characteristics can be seen as potential risk factors for the development of DR, particularly those changeable.

Our results show that an increased duration of diabetes, poorly controlled cholesterol level and raised BMI are characteristics associated with an increased risk of DR. Across the globe, in various population groups, a great number of studies have been 
Table 2. Comparison of characteristics in patients with diabetes and with retinopathy or without retinopathy $(N=600)$

\begin{tabular}{|c|c|c|c|}
\hline \multirow{2}{*}{$\begin{array}{l}\text { Patient characteristics } \\
\text { (potential risk factors) }\end{array}$} & $\begin{array}{c}\text { No retinopathy } \\
n=333\end{array}$ & $\begin{array}{c}\text { Retinopathy } \\
n=267\end{array}$ & \multirow{2}{*}{$\begin{array}{c}T \text { test } \\
\mathrm{p} \text {-value }\end{array}$} \\
\hline & Mean (SD) & Mean (SD) & \\
\hline Male (n, \%) & $173(51.9)$ & $136(50.9)$ & ns\# \\
\hline Age (years) & $63.6(15.6)$ & $67.5(10.2)$ & $<0.001$ \\
\hline Age at diagnosis (years) & $53.2(15.1)$ & $51.4(11.9)$ & 0.106 \\
\hline Duration of diabetes (years) & $10.4(5.1)$ & $16.1(7.3)$ & $<0.001$ \\
\hline $\mathrm{HbA}_{1} \mathrm{c}(\%)$ & $6.0(0.4)$ & $6.4(0.5)$ & $<0.001$ \\
\hline BMI $\left(\mathrm{kg} / \mathrm{m}^{2}\right)$ & $26.2(2.8)$ & $28.3(2.8)$ & $<0.001$ \\
\hline Hypertension (\%) & $121.0(33.3)$ & $95.0(26.7)$ & 0.079 \\
\hline $\mathrm{SBP}(\mathrm{mmHg})$ & $138.0(11.9)$ & $141.0(14.1)$ & 0.123 \\
\hline $\mathrm{DBP}(\mathrm{mmHg})$ & $83.0(3.9)$ & $88.0(1.5)$ & 0.080 \\
\hline Cholesterol (mmol/l) & $4.6(0.9)$ & $5.0(1.0)$ & $<0.001$ \\
\hline Triglycerides (mmol/l) & $1.5(0.9)$ & $1.5(0.5)$ & 0.370 \\
\hline
\end{tabular}

$\mathrm{HbA}_{1} \mathrm{C}$ - glycated haemoglobin; BMI - body mass index; SBP - systolic blood pressure; DBP - diastolic blood pressure; ns - not significant; \# Chi-square test

Table 3. Prevalence and level of retinopathy related to duration of diabetes $(N=600)$

\begin{tabular}{|c|c|c|c|c|c|c|}
\hline & \multirow[b]{2}{*}{$\begin{array}{l}\text { Duration } \\
\text { of diabetes (years) }\end{array}$} & \multicolumn{5}{|c|}{ Level of retinopathy } \\
\hline & & $\begin{array}{l}\text { No DR } \\
(n=37)\end{array}$ & $\begin{array}{l}\text { Mild NPDR } \\
\qquad(n=6)\end{array}$ & $\begin{array}{c}\text { Moderate-severe } \\
\text { NPDR } \\
(n=8)\end{array}$ & $\begin{array}{l}\text { PDR } \\
(n=4)\end{array}$ & $\begin{array}{l}\text { Total } \\
(n=55)\end{array}$ \\
\hline \multirow{7}{*}{$\begin{array}{l}\text { Diabetes mellitus } \\
\text { type } 1 \\
(n=55)\end{array}$} & $\leq 1$ & 0 & 0 & 0 & 0 & 0 \\
\hline & $2-5$ & 9 & 1 & 0 & 0 & 10 \\
\hline & $6-10$ & 15 & 0 & 0 & 1 & 16 \\
\hline & $11-15$ & 11 & 1 & 3 & 0 & 15 \\
\hline & $16-20$ & 1 & 1 & 1 & 1 & 4 \\
\hline & $>20$ & 1 & 3 & 4 & 2 & 10 \\
\hline & $\begin{array}{c}\text { Duration } \\
\text { of diabetes (years) }\end{array}$ & $\begin{array}{c}\text { No DR } \\
(n=296)\end{array}$ & $\begin{array}{l}\text { Mild NPDR } \\
(n=118)\end{array}$ & $\begin{array}{c}\text { Moderate-severe } \\
\text { NPDR } \\
(n=105)\end{array}$ & $\begin{array}{c}\text { PDR } \\
(n=26)\end{array}$ & $\begin{array}{l}\text { Total } \\
(n=545)\end{array}$ \\
\hline \multirow{6}{*}{$\begin{array}{l}\text { Diabetes mellitus } \\
\text { type } 2 \\
(n=545)\end{array}$} & $\leq 1$ & 9 & 0 & 0 & 0 & 9 \\
\hline & $2-5$ & 35 & 6 & 3 & 0 & 44 \\
\hline & $6-10$ & 101 & 21 & 17 & 1 & 140 \\
\hline & $11-15$ & 113 & 43 & 46 & 11 & 213 \\
\hline & $16-20$ & 27 & 21 & 22 & 9 & 79 \\
\hline & $>20$ & 11 & 27 & 17 & 5 & 60 \\
\hline
\end{tabular}

DR - diabetic retinopathy; NPDR - non-proliferative diabetic retinopathy; PDR - proliferative diabetic retinopathy

performed looking at potential risk factors for the development of DR. A number of studies have found, like us, that a longer duration of diabetes, poorly controlled $\mathrm{HbA}_{1} \mathrm{c}$ and raised $\mathrm{BMI}$ are associated with an increased risk of DR (9-15). In contrast to our results many studies have also found high blood pressure, poor glycaemic control and proteinuria to be risk factors for the development of DR (16-20). Such information is necessary in order to facilitate timely intervention, development of preventative procedures, and for the planning of future screening services for DR.

Additionally, the presence of DR could also be considered an indicator of microcirculatory dysfunction in other vital organs in the body as well as in the eye (21). Some studies suggest that the presence of DR may be linked to an increased risk of systemic vascular complications, such as coronary heart disease, stroke and nephropathy (22-26). Therefore, an increase in awareness of DR and its risk factors will enable better comprehension of systemic diabetic complications.

Visual impairment as a result of DR has a significant impact on the quality of life of affected patients $(27,28)$ and can compromise their ability to successfully manage their disease, which can in turn have a negative impact on the incidence of other diabetic complications and even overall life expectancy of patients (29). Consequently, early detection and management of DR in patients with diabetes is essential in preserving quality of life for affected individuals. 


\section{CONCLUSION}

Our results show, for the first time, the prevalence rates of DR for the Dubrovnik-Neretva County in the Republic of Croatia. The incidence and prevalence of diabetes mellitus in our County follow and even exceeded rates reported in the developed countries whilst at the same time facilities for the detection and treatment of DR remain limited. The results of this study serve to highlight the need for a greater orientation of healthcare services to the earlier detection of DR. Our findings pertaining to the duration of diabetes poorly controlled $\mathrm{HbA}_{1} \mathrm{c}$ and raised $\mathrm{BMI}$ as risk factors for the development of DR further emphasize the need of screening and early detection of DR particularly in the most susceptible patient group.

\section{Declaration of Authorship}

Antonela Gverović Antunica and Helena Kaštelan designed the study, analyzed and interpreted the data. Kajo Bućan analyzed and interpreted the data and co-authored the manuscript. Mira Ivanković performed the clinical research and collected the data, Snježana Kaštelan and Maja Šikić interpreted the data and provided scientific input.

\section{Conflict of Interests}

None declared

\section{REFERENCES}

1. King H, Aubert RE, Herman WH. Global burden of diabetes, 19952025: prevalence, numerical estimates, and projections. Diabetes Care. 1998;21(9):1414-31.

2. Wild S, Roglic G, Green A, Sicree R, King H. Global prevalence of diabetes estimates for the year 2000 and projections for 2030. Diabetes Care. 2004;27(5):1047-53.

3. Tracey ML, McHugh SM, Fitzgerald AP, Buckley CM, Canavan RJ, Kearney PM. Trends in blindness due to diabetic retinopathy among adults aged 18-69years over a decade in Ireland. Diabetes Res Clin Prac. 2016;121:1-8.

4. Klein R, Klein BE, Moss SE, Davis MD, DeMets DL. The Wisconsin epidemiologic study of diabetic retinopathy. III. Prevalence and risk of diabetic retinopathy when age at diagnosis is 30 or more years. Arch Ophthalmol. 1984;102(4):527-32.

5. Klein R, Klein BE, Moss SE. The Wisconsin epidemiological study of diabetic retinopathy: a review. Diabetes Metab Rev. 1989;5(7):559-70.

6. Wu L, Fernandez-Loaiza P, Sauma J, Hernandez-Bogantes E, Masis M. Classification of diabetic retinopathy and diabetic macular edema. World J Diabetes. 2013;4(6):290-4.

7. Leasher JL, Bourne RR, Flaxman SR, Jonas JB, Keeffe J, Naidoo K, et al. Global estimates on the number of people blind or visually impaired by diabetic retinopathy: a meta-analysis from 1990 to 2010. Diabetes Care. 2016 Sep;39(9):1643-9.

8. Thomas RL, Dunstan FD, Luzio SD, Chowdhury SR, North RV, Hale $\mathrm{SL}$, et al. Prevalence of diabetic retinopathy within a national diabetic retinopathy screening service. Br J Ophthalmol. 2015 Jan;99(1):64-8.

9. Kaštelan S, Tomić M, Antunica Gverović A, Rabatić Salopek J. Obesity and retinopathy in diabetes. J Mol Genet Med. 2014;Spec No 1:020. doi:10.4172/1747-0862.S1-020.

10. Keel S, Itsiopoulos C, Koklanis K, Vukicevic M, Cameron F, Brazionis L. Prevalence and risk factors for diabetic retinopathy in a hospital-based population of Australian children and adolescents with type 1 diabetes. J Pediatr Endocrinol Metab. 2016 Oct 1;29(10):1135-42.
11. Yan ZP, Ma JX. Risk factors for diabetic retinopathy in northern Chinese patients with type 2 diabetes mellitus. Int J Ophthalmol. 2016 Aug 18;9(8):1194-9.

12. Zhang X, Saaddine JB, Chou CF, Cotch MF, Cheng YJ, Geiss LS, et al. Prevalence of diabetic retinopathy in the United States, 2005-2008. JAMA. 2010 Aug 11;304(6):649-56.

13. Kaštelan S, Tomić M, Gverović Antunica A, Ljubić S, Salopek Rabatić J, Karabatić M. Body mass index: a risk factor for retinopathy in type 2 diabetic patients. Mediators Inflamm. 2013;2013:436329. doi: $10.1155 / 2013 / 436329$

14. Tomić M, Ljubić S, Kaštelan S, Gverović Antunica A, Jazbec A, Poljičanin T. Inflammation, haemostatic disturbance, and obesity: possible link to pathogenesis of diabetic retinopathy in type 2 diabetes. Mediators Inflamm. 2013;2013:818671. doi: 10.1155/2013/818671.

15. Kaštelan S, Salopek Rabatić J, Tomić M, Gverović Antunica A, Ljubić $\mathrm{S}$, Kaštelan H, et al. Body mass index and retinopathy in type 1 diabetic patients. Int J Endocrinol. 2014;2014:387919. doi: 10.1155/2014/387919.

16. Bertelsen G, Peto T, Lindekleiv H, Schirmer H, Solbu MD, Toft I, et al. Tromsø eye study: prevalence and risk factors of diabetic retinopathy. Acta Ophthalmol. 2013 Dec;91(8):716-21.

17. Jee D, Lee WK, Kang S. Prevalence and risk factors for diabetic retinopathy: the Korea National Health and Nutrition Examination Survey 2008-2011. Invest Ophthalmol Vis Sci. 2013 Oct 17;54(10):6827-33.

18. Zheng Y, Lamoureux EL, Lavanya R, Wu R, Ikram MK, Wang JJ, et al. Prevalence and risk factors of diabetic retinopathy in migrant Indians in an urbanized society in Asia: the Singapore Indian eye study. Ophthalmology. 2012 Oct;119(10):2119-24.

19. Penman A, Hancock H, Papavasileiou E, James M, Idowu O, Riche DM, et al. Risk factors for proliferative diabetic retinopathy in African Americans with Type 2 Diabetes. Ophthalmic Epidemiol. 2016;23(2):88-93.

20. Klein R, Moss S, Klein B. Is gross proteinuria a risk factor for the incidence of proliferative diabetic retinopathy? Ophthalmology. 1993 Aug;100(8):1140-6.

21. Chaturvedi N, Porta M, Klein R, Orchard T, Fuller J, Parving HH, et al. DIRECT Programme Study Group Effect of candesartan on prevention (DIRECT-Prevent 1) and progression (DIRECT-Protect 1) of retinopathy in type 1 diabetes: randomised, placebo-controlled trials. Lancet. 2008;372(9647):1394-1402.

22. Rodríguez-Poncelas A, Mundet-Tudurí X, Miravet-Jiménez S, Casellas A, Barrot-De la Puente JF, Franch-Nadal J, et al. Chronic kidney disease and diabetic retinopathy in patients with type 2 diabetes. PLoS One. 2016 Feb 17;11(2):e0149448. doi: 10.1371/journal.pone.0149448.

23. Guo VY, Cao B, Wu X, Lee JJ, Zee BC. Prospective association between diabetic retinopathy and cardiovascular disease-a systematic review and meta-analysis of cohort studies. J Stroke Cerebrovasc Dis. 2016 Jul;25(7):1688-95.

24. Um T, Lee DH, Kang JW, Kim EY, Yoon YH. The Degree of Diabetic Retinopathy in patients with Type 2 Diabetes correlates with the presence and severity of Coronary Heart Disease. J Korean Med Sci. 2016 Aug; 31(8):1292-9.

25. Pedro RA, Ramon SA, Marc BB, Juan FB, Isabel MM. Prevalence and relationship between diabetic retinopathy and nephropathy, and its risk factors in the North-East of Spain, a population-based study. Ophthalmic Epidemiol. 2010 Aug;17(4):251-65.

26. He F, Xia X, Wu XF, Yu XQ, Huang FX. Diabetic retinopathy in predicting diabetic nephropathy in patients with type 2 diabetes and renal disease: a meta-analysis. Diabetologia. 2013 Mar;56(3):457-66.

27. Frank RN. Etiologic mechanisms in diabetic retinopathy. In: Ryan SJ, Hinton DR, Schachat AP, Wilkinson CP, editors. Retina. St Louis: Mosby; 1994. p. 1243-76.

28. Diabetes Mellitus. World Health Organ Tech Rep Ser. 1985;(727):1-113.

29. Frank RN. On the pathogenesis of diabetic retinopathy. A 1990 update. Ophthalmology. 1991;98(5):586-93. 